\title{
RANCANG BANGUN PENGOLAHAN DATAPADA DESA BATU TERING SEBAGAI MEDIA PROMOSI DAN INFORMASI WISATA BERBASIS WEB
}

\author{
Tomy Dwi Cahyono ${ }^{1}$, Firmansyah Putra ${ }^{2}$, M.Julkarnaen ${ }^{3}$ \\ Tomy.dwi.cahyono@uts.ac.id, Firmansyahp02@gmail.com, M.Julkarnain@uts.ac.id \\ 1) Program Studi Informatika, Fakultas teknik, Universitas Teknologi Sumbawa \\ 2) Jl.Olat Maras Batu Alang-Sumbawa Besar
}

\begin{abstract}
Abstraksi
Pengolahan Data pada Desa Batu Tering Sebagai Media promosi dan informasi Berbasis Web saat ini sangat diperlukan terutama dalam memperkenalkan sebuah daerah. Pengolahan data ini berfokus pada pelayanan impormasi dan pormosi wisata sehingga membantu mengembangkan media informasi dalam promosi desa, potensi, dan produk yang ada. Mempermudah masyarakat medapatkan informasi tentang desa batu tering, serta dapat melakukan proses pemesanan produk, pada Desa Batu Tering. Hasil akhir dari penelitian ini adalah Pengoahan Data Pada Desa Batu Tering Sebagai MediaPromosi Dan Informasi Wisata Berbasis Web. Sehingga membantu mewujudkan Visi dalam mempromosikan produk dan wisata yang ada di Desa Batu Tering melalui web, Memudahkan pemerintah desa dalam memberikan informasi untuk mempromosikan wisata, potensi, dan produk yang bisa di pesan langsung lewat web oleh masyarakat luas,Memudahkan pengguna dalam mengakses informasi pada Desa Batu Tering.
\end{abstract}

Kata Kunci: Pengolahan Data, Administratoristrasi, WEB, PHP, Waterfall, Black-box

\begin{abstract}
Data Processing in Batu Tering Village As a media for promotion and information Web-based is currently very much needed especially in introducing an area. This data processing focuses on information services and tourism promotion so as to help develop information media in village promotion, potential, and existing products. Make it easier for the public to obtain information about the village of tering stone, and can process the product order, in Batu Tering Village. The final result of this research is Data Processing in the Tering Stone Village as a Web-Based Promotion and Tourism Information Media. So as to help realize the vision in promoting products and tourism in Batu Tering Village through the web, facilitating village governments to provide information to promote tourism, potential, and products that can be ordered directly through the web by the wider community, making it easier for users to access information on the village Tering Stone.
\end{abstract}

Keywords: Data Processing, Administrator, WEB, PHP, Waterfall, Black-box 


\section{RANCANG BANGUN PENGOLAHAN DATAPADA DESA BATU TERING SEBAGAI MEDIA PROMOSI DAN INFORMASI WISATA BERBASIS WEB}

\section{PENDAHULUAN}

Media promosi dan informasi saat ini sangat diperlukan terutama dalam memperkenalkan sebuah daerah. Objek wisata, potensi yang ada di Desa Batu Tering merupakan suatu kekayaan alam serta produk yang patut untuk dibanggakan. Objek wisata , potensi serta produk yang ada di desa Batu Tering dalam bidang pertanian dan peternakan yang menjadi produk desa yang harus diketahui oleh masyarakat luas, juga harus disebar luaskan. Tetapi terdapat kendala dikarenakan belum tersedianya media informasi khusus Desa Batu Tering Kecamatan Moyo Hulu.

Dalam melakukan promosi masyarakat desa serta pemerintah desa hanya mengandalkan papan nama wisata di samping jalan, dari mulut ke mulut serta spanduk yang tidak efektif dalam menyebarkan informasi. Perkembangan serta kemajuan teknologi saat ini hingga perkembangan ekonomi di sejumlah daerah, membuat masayarakat luas sekarang lebih senang memilih cara instan mereka, yaitu melalui media internet.

Berdasarkan permasalahan dalam penjelasan diatas, maka penulis ingin membuat web dengan judul yang diangkat dalam tugas akhir (TA) yaitu "Rancang Bangun Pengolahan Data Pada Desa Batu Tering Sebagai Media Promosi Dan Informasi Wisata Berbasis Web".

Adapun tujuan dari penelitian ini dibuat berdasarkan dari penelitian yang akan dilakukan adalah pengolahan data pada Desa Batu Tering sebagai media promosi dan informasi wisata berbasis web, untuk membantu mengembangkan media informasi dalam promosi desa, potensi, dan produk yang ada. Sehingga membantu mewujudkan Visi dalam mempromosikan produk dan wisata yang ada di Desa Batu Tering melalui web.

\section{TINJAUAN PUSTAKA}

Sebagai perbandingan penelitian ini, peneliti menggunakan beberapa sumber acuaan diantaranya.Arsyad (2011) Perancangan Sistem informasi Parawisata Berbasis Web Di Dinas Kebudayaan Dan Pariwisata Kabupaten Muna. Persamaan antara penelitian inni dengan penelitian yang peneliti lakukan adalah sama-sama menggunakan berbasis Web dengan teknik wawancara, bahasa yangdigunakan adalah PHP dengan database Web dan metode pengembangan perangkat lunak waterfall dan metode pengembangan sistem menggunakan Data Flow Diagram (DFD). Perbedaanya terletak pada perancangan sistem informasi sedangkan pada penelitian ini adalah aplikasi.
Amelia (2015) dengan judul Perancangan Media Promosi PT Petronika Sebagai Upaya Pembentukan Citra Perusahaan. Persamaan antara penelitian ini dengan penelitian yang peneliti lakukan adalah pada metode yang digunakan yaitu metode kualitatif, sedangkan perbedaan terletak pada metode pengembangan perangkat lunak, pada laporan ini menggunakan metode waterfall sedangkan pada penelitian yang dilakukan Amelia tidak menggunkan metode tersebut.

\subsection{Desa}

Menurut Widjaja (2003). Desamerupakankesatuan masyarakat hukum yang mempunyai susunan asli berdasarkan hak asal usul yang bersifat istimewa dan komunitas kecil yang terkait pada lokalitas tertentu baik sebagai tempat tinggal dan juga dalam memenuhi kebutuhan hidup masyarakat desa yang bergantung pada pertanian

\subsection{Promosi}

Menurut Rangkuti (2009).Promosi adalah kegiatan penjualan dan pemasaran dalam rangka menginformasikan dan mendorong permintaan produk, jasa, ide dari perusahaan dengan cara mempengaruhi konsumen agar mau produk dan jasa oleh perusahaan.

mempengaruhi perusahaan yang bersangkutan.

\section{$1.3 \mathrm{Web}$}

Menurut Yuhefizar (2010) web merupakan kumpulan halaman web yang menampilkan berbagai informasi baik itu teks, gambar, data, animasi, video, suara ataupun gabungan dari semuaitu, yang membentuk menjadi satu rangkaian yang saling berkaitan dan dihubungkan dengan jaringan halaman web yang terdapat dalam sebuah domain yang mengandung informasi.

\subsection{Metode Waterfall}

Menurut Pressman (2015)Model waterfalladalah model klasik yang bersifat sistematis, berurutan dalam membangunsoftware. Namamodelinisebenarnyaadala $\mathrm{h}$ “Linear SequentialModel”. Model iniseringdisebut jugadengan "classic lifecycle" atau metodewaterfall. Model initermasuk kedalam modelgenericpadarekayasa perangkat lunak dan pertamakalidiperkenalkan oleh Winston Roycesekitar tahun1970sehinggasering dianggapkuno,tetapimerupakanmodelyang paling banyak dipakaidalamSoftware Engineering(SE). Model inimelakukan pendekatansecarasistematis danberurutan.Disebutdenganwaterfallkarena tahapdemitahapyang dilaluiharusmenungguselesainyatahapsebelumnyada $\mathrm{n}$ berjalan berurutan.

1.5 Metode Pengujian Perangkat Lunak (Black Box). 


\section{RANCANG BANGUN PENGOLAHAN DATAPADA DESA BATU TERING SEBAGAI MEDIA PROMOSI DAN INFORMASI \\ WISATA BERBASIS WEB}

Menurut Pressman (2015). Black-box testing atau disebut juga behavioral testing berfokus pada persyaratan fungsional perangkat lunak. Black-box testing memungkinkan penguji perangkat lunak untuk melakukan serangkaian pengujian berdasarkan masukan (input) sesuai dengan kondisi tertentu yang akan mengerjakan tugas - tugas dari keseluruhan kebutuhan fungsi sebuah program.

Black-box testing berusaha mencari kesalahan kesalahan yang dikelompokkan dalam kategori berikut :
1) Kesalahan atau kekurangan fungsi.
2) Kesalahan tampilan aplikasi.
3) Kesalahan pada struktur

\section{METODOLOGI PENELITIAN}

\subsection{Metode Penelitian}

Tahap-

tahapyangdilakukandalampengumpulandatauntukme mbangun datainformasi inidapatdigambarkan padabagan alur sebagaiberikut:

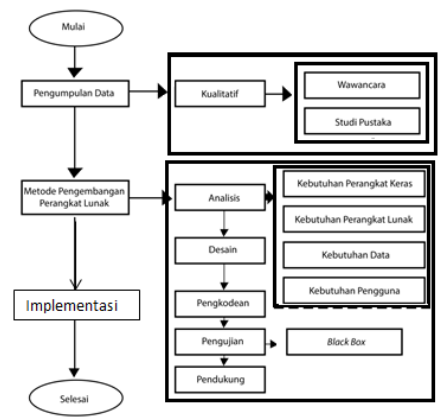

Gambar 3.1 Alur Penelitian

PadaGambar3.1diatasmenggambarkanalurpeneli tianyang dimulaidari pengumpulandata menggunakanmetodepenelitian kualitatifyang terdiridari wawancara.Teknikwawancara ini dilakukan secara langsung untuk

mewawancarai kepada responden yaitu kepala desa,danteknikstudipustaka berupa pengumpulan data, data yg dibutuhkan dalam penelitian.Kemudianmemulai tahapan penelitian menggunakan metode pengembangan perangkat lunak waterfallyangterdiridaritahap analisis,desain,pengkodean,pengujiandan pendukung.

\subsubsection{Metode Pengumpulan Data}

Metodepengumpulandataadalah

teknikyang digunakandalam mengumpulkandatadaninformasiterkaitdenganpeneli tianyang dilaksanakan olehpenulis untukmenyelesaikantugas akhirskripsiini.Metodepengumpulan datayangdigunakan sebagaiberikut:

dalampenelitianiniadalah

Wawancara,pada metode iniwawancaradilakukanuntuk mengumpulkan data secara langsungdengan cara melakukan tanya jawab dengan narasumber, dalampenelitianskripsiinipenulis

melakukanwawancaradenganBapak Mujiburrahman, selakuKepalaDesa Batu Tering,mengenaipengadaan pengolahan data berbasis web yang akandibangun,serta

mewawancarainarasumberterkaityang berhubungan dengan objekyangakan diteliti.

StudiPustaka,metodepengumpulan data inidilakukandengancaramemperhatikanreferensiataul iteraturyang mendukung dalampenyusunan skripsiini,datainformasiyang

diambildaripengumpulandata iniadalah dasar-dasar teori, dan ketersediaan narasumber untuk mendukungpenelitian skripsiini.

\subsubsection{MetodePengembangan Perangkat Lunak}

Adapunmetode yanag diunakanpengembanganperangkatlunakyangdigunak andalam penelitianskripsiiniadalahmetodewaterfallyaitupemo delanyang menyediakan pendekatan alur hidup perangkat lunak secara sekuensial atau terurutdimulaidari analisis, desain, pengodean, pengujian dan tahap pendukung sepertimaintenance(pemeliharaan).Adapunalur metodewaterfalldapatdilihat sebagai berikut:

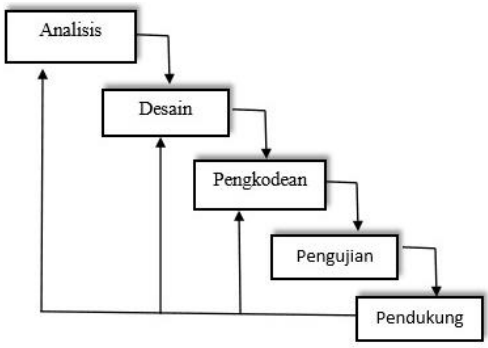

\section{Gambar 3.2 MetodeWaterfall}

Berikut adalahtahapan-tahapan metode pengembangan perangkat lunak waterfalldalampenelitian skripsi:

\section{a. AnalisisKebutuhan}

\section{Proses}

pengumpulankebutuhanperangkatlunak, perangkatker as, kebutuhanpenggunadankebutuhandatadilakukan secaraintensifagarsesuai dengan spesifikasidan alternatif yangdibutuhkan untuk membangun aplikasi. 


\section{RANCANG BANGUN PENGOLAHAN DATAPADA DESA BATU TERING SEBAGAI MEDIA PROMOSI DAN INFORMASI WISATA BERBASIS WEB}

b. Desain

Desainperangkatlunak bagiandariprosesperancanganyang meliputisistem, basis

adalah interfaceuntukmelihatgambaranumum desain serta segala fungsional yang diperlukan oleh pengguna sistem nantinya.

c. Pengkodean

Darirancangan desain antarmukayangtelah dibuat, selanjutnyadesain

harusdiimplementasikankedalamperangkatlunakagar menjadiprogram yang

dapatdioperasikanolehpenggunasesuaidenganrancan ganyang telah ditentukan,dimanapenulisakan menerjemahkandesainsistemdalambahasa

pemrograman PHPdan Websitesebagaisistem manajemen basisdata.

\section{d. Pengujian}

Tahappengujiandilakukanuntukmemastikanbahw asemuabagian dariprogramyangtelahdibangundapat dioperasikandenganbaiksehingga dapatmeminimalisirkesalahan(error)yang

terjadi,sertamemastikan kesesuaianprogramdengan yangdiinginkan.Padatahappengujiandalam penelitian skripsiini, penulismenggunakan metodeblackbox.

e. Pendukung

pemeliharaan(maintenance)

(support)atau

Setelah programmelaluitahappengujian tidak menutupkemungkinan sebuahsistemaplikasimengalamiperubahandatasetela h programsudah dikirimkanke pengguna,makauntukpengelolahanaplikasiakandisera hkan kepadapihak yangterkaitobjek penelitianskripsi ini.

\section{HASIL DAN PEMBAHASAN}

4.1 Hasil Rancangan Sistem

Berikut ini merupakan hasil rancangan sistem yang dikerjakan dalam pembuatan pengolahan data pada desa Batu tering sebagai media promosi dan informasi wista berbasis web.

4.1.1 Flowmap

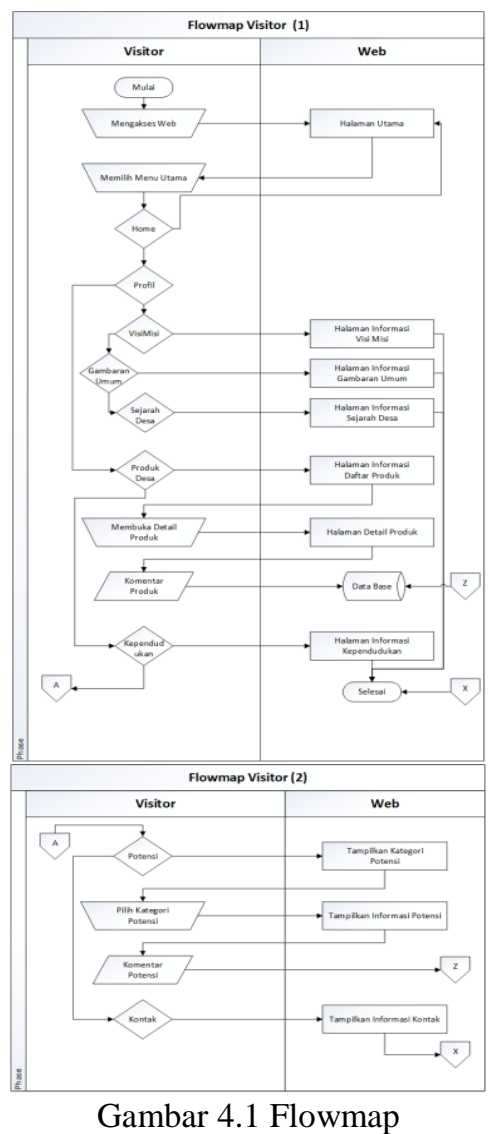

\subsubsection{Flowmap}

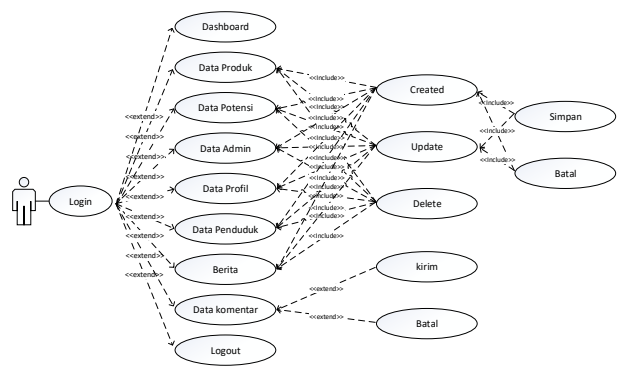

Gambar 4.2 use Case Diagram

Pada use case diagram di atas menggambarkan bahwa ketika ctor (user) berinteraksi dengan web actor akan dihadapkan dengan enam aktifitas utama yang dapat dilakukan yang disajikan dalam bentuk menu web. Dari keenam menu tersebut dua diantaranya memiliki sub menu, yaitu menu profil dan potensi.

\subsubsection{Activity Diagram}




\section{RANCANG BANGUN PENGOLAHAN DATAPADA DESA BATU TERING SEBAGAI MEDIA PROMOSI DAN INFORMASI WISATA BERBASIS WEB}

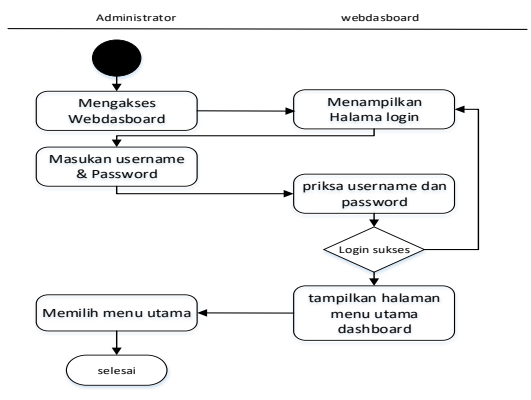

Gambar 4.3 Activity Diagram

Pada activity diagram di atas menjelaskan bahwa ketika administrator ingin mengakses halaman utama web dashboard administrator harus melakukan proses login terlebih dahulu. Setelah login berhasil administrator dapat memilih menu utama yang terdapat pada halaman utama dashboard.

\subsubsection{Sequence Diagram}

Rancangan sequence diagram bertujuan mendeskripsikan bagaimana interaksi antara objek yang terdapat dalam web. Pada rancangan sequence diagram pengolahan data pada desa Batu Tering sebagai media promosi dan informasi wista berbasis webterdapat dua sequence diagram yaitu sequence diagram user dan sequence diagram administrator .Berikut perancangannya.

a. Sequence Diagram User

1) Sequence Diagram Home

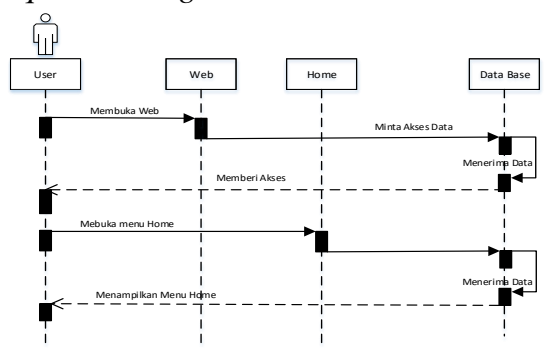

Gambar 4.4Sequence Diagram Home

Pada use case diagram home menjelaskan bahwa ketika visitori mengakses web desa Batu Tering maka web akan memanggil halaman home yang di dalamnya terdapat beberap menu utama.

2) Sequence Diagram Produk Desa

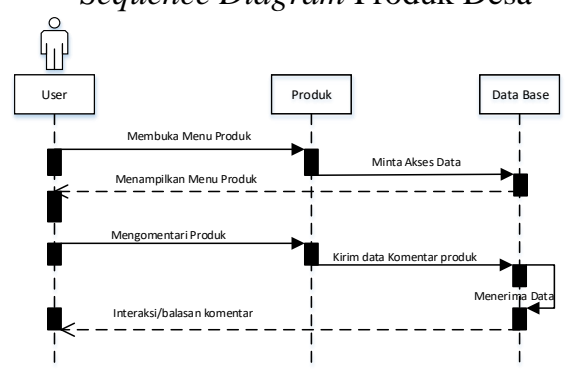

Gambar 4.5Sequence Diagram Produk Desa
Pada sequence diagram produk desa menjelakan bahwa ketika visior memilih menu produk desa pada halaman utama, maka visior tersebut dapat melilhat dan mengomentari produk desa yang ada.

\section{b. Sequence Diagram Administrator}

1)

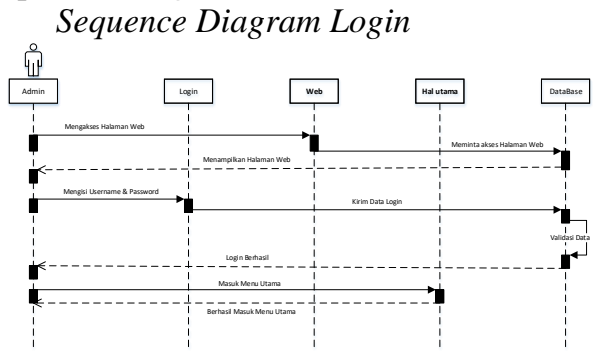

Gambar 4.6Sequence Diagram Login

Pada sequence diagram Login menjelaskan bahwa ketika administrator mengakses web, maka visitor akan masuk ke halaman login,saat login administrartor akan memsukan username dan password, setelah itu visitor akan masuk ke menu utama dan berhasil masuk.

\section{2) Sequence Diagram Data Produk}

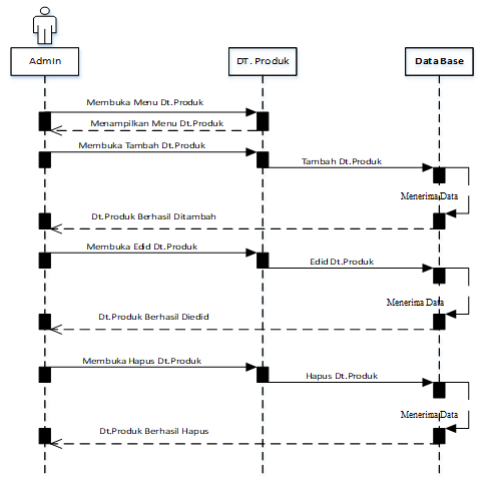

Gambar 4.7Sequence Diagram Data Produk

Pada sequence diagram Data Produk menjelaskan bahwa ketika administrator mengakses Data Produk,dan ditampilkn di halaman admin. Setelah itu admin menambahkan produk dan meminta data dari database dan data produk berhasil di tambah. Begitu pula alur dari hapus dan edit data produk.

\subsection{Class Diagram}

Rancangan class diagram bertujuan untuk mendeskripsikan interaksi tiap-tiap class yang ditunjukkan dengana garis yang menghubungkan antar class. Berikut adalah rancangan class diagram pada pengolahan data pada desa Batu Tering sebagai media promosi dan informasi wista berbasis web. 


\section{RANCANG BANGUN PENGOLAHAN DATAPADA DESA BATU TERING SEBAGAI MEDIA PROMOSI DAN INFORMASI WISATA BERBASIS WEB}
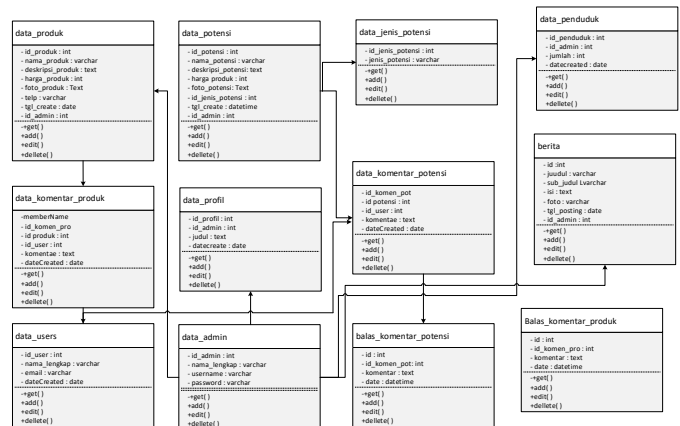

Gambar 4.8 Class Diagram

\subsection{Rancangan Tampilan}

\subsubsection{Rancangn Tampilan Administrator}

Adapun perancangan dari tampilan administrator yaitu:

a. Tampilan Login

Berikut ini rancangan tampilan loginyaitu :

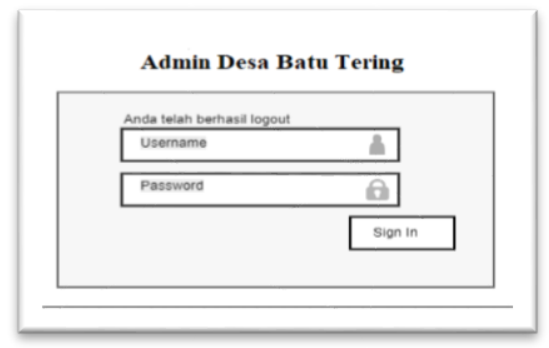

Gambar 4.9 Tampilan Perancangan Login

Rancangan tampilan login merupakan rancangan tampilan awal ketika sistem pertama kali dijalankan.Pada tampilan ini terdapat kolom untuk memasukan username dan password serta tombol button untuk login.

b. Rancangan Tampilan Data Produk

Berikut ini adalah rancangan tampilan data produk pada administrator :

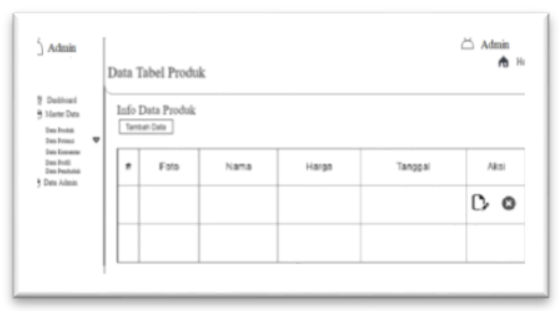

Gambar.4.10Tampilan Perancangan Halaman Data Produk

Pada rancangan tampilan data produk akan menampilkan produk yang telah diinput oleh administrator, dan administrator juga dapat mengedit dan menghapus produk yang sudah ditambahkan, di data produk terdapat foto produk, nama produk,harga produk, serta tanggal produk.

\subsubsection{Rancangan Tampilan Customer}

a. Tampilan Halaman Utama

Adapun rancangan tampilan halaman utama pada customer:

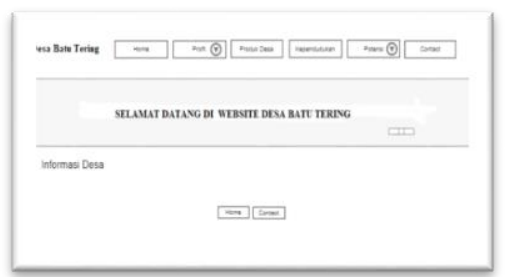

Gambar 4.11 Tampilan Perancangan Halaman Utama

Pada menu halaman utama pada customer, akan menampilkan informasi terbaru dari desa Batu Tering kemudian user dapat memilih menu home, menu profil, dalam menu profil terdapat visi \& misi, gambaran umum desa, dan sejarah desa, kemudian ada menu produk, menu kependudukan, menu berbagai potensi yakni sumber daya alam, wisata, budaya dan adat istiadat dan terdapat menu kontak.

b. Tampilan Halaman Produk

Adapun rancangan tampilan halaman profil pada sejarah desa padacustomer :

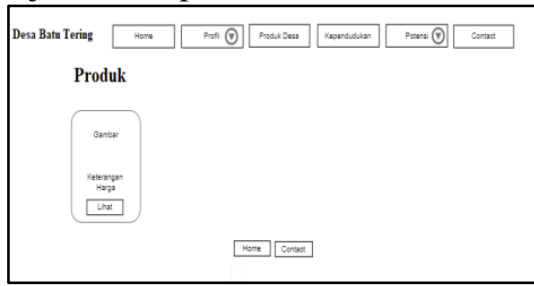

Gambar 4.12 Tampilan Perancangan Halaman Produk Desa

Pada menu halaman tampilan produk desa di customer, akan menampilkan gambar produk, komentar dan informasi disertai harga kemudian terdapat menu lihat yang diarahkan langsung ke produk desa secara detail besertai pemesanan produk yang akan dibeli oleh customer.

\subsection{Implementasi Tampilan}

\subsubsection{Tampilan Halaman Administrator}

Berikut ini adalah tampilan halaman administratorRancang Bangun pengolahan data pada Desa Batu Tering sebagai media promosi dan informasi wisata berbasis web meliputi :

a. Login

Berikut ini adalah tampilan halaman loginRancang Bangun pengolahan data pada Desa Batu Tering sebagai media promosi dan informasi wisata berbasis web: 


\section{RANCANG BANGUN PENGOLAHAN DATAPADA DESA BATU TERING SEBAGAI MEDIA PROMOSI DAN INFORMASI WISATA BERBASIS WEB}

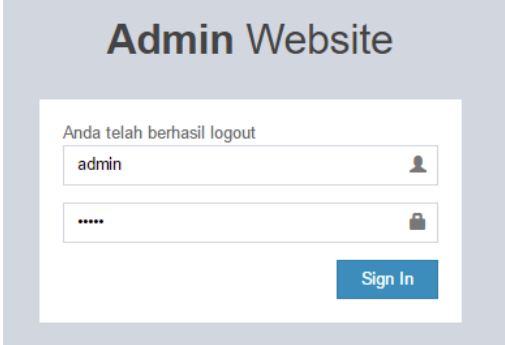

Gambar 4.13 Tampilan Implementasi Login

Login merupakan tampilan awal ketika sistem pertama kali dijalankan.Pada tampilan ini terdapat kolom untuk memasukan username dan password serta tombol button untuk login.

\section{b. Data Produk}

Data produk memiliki peran utama dari sebuah Pengolahan Data Pada Desa Batu Tering Sebagai Media Promosi Dan Informasi Wisata Berbasis Web.

Berikut ini tampilan halaman data produk pada Rancang Bangun Penolahan Data Pada Desa Batu Tering Sebagai Media Promosi Dan Informasi Wisata Berbasis Web:

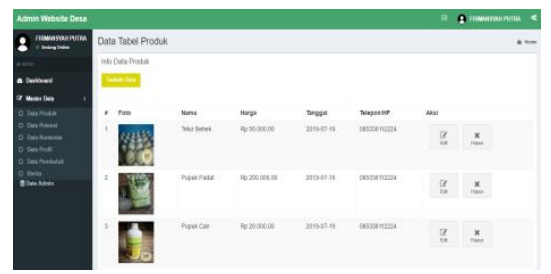

Gambar 4.14 Tampilan Implementasi Data Produk

Adapun data produk di sini adalah tampilan halaman yang dibuat pada administrator untuk mempermudah dalam mengelolah data produk. Administrartor dapat menambah,menghapus dan megedit data produk yang ada

\subsubsection{Customer}

Data customer merupakan data pengguna yang memiliki akses untuk melihat informasi desa dan dapat mengomentari item produk ataupun potensi dan dapat memesan produk sesuai dengan apa yang diinginkan melalui telepon.

a. Halaman Home

Berikut ini adalah tampilan halaman home :

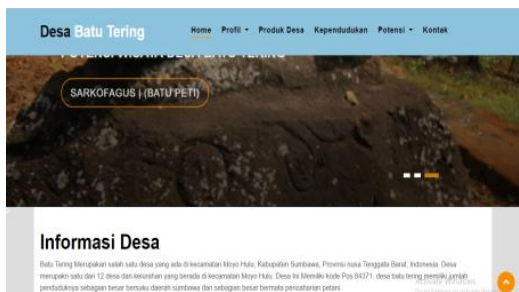

Gambar 4.15Tampilan ImplementasiHome
Pada tampilan halaman hom terdapat menu yang enam menu diantaranya menu home,profil,produk desa,kependudukan,potensi serta kontak.

\section{b. Halaman Produk Desa}

Berikut ini adalah tampilan halaman produk desa yang memiliki beberapa halaman didalamnya yaitu sebagai berikut :

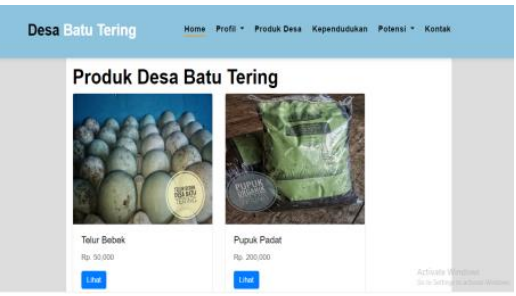

Gambar 4.16 Tampilan Implementasi Produk Desa

Pada halaman produk desa.Penunjung dapat melihat produk yang ada dan dapat berinteraksi lewat komentar dalam sistem pemesanan produk.

\subsection{Pengujian}

Adapun hasil dari pengujian perangkat lunak yang dilakukan menggunakan metode pengujian black box yaitu sebagai berikut:

\subsubsection{Pengujian Sistem Administrator}

Pengujian perangkat lunak pada sisten administrator terdiri dari login, dashboar, data produk,data potensi, data profil, data penduduk dan data administrator

a. Hasil Pengujian Login Pada Sistem Administrator.

Adapun pengujian login pada sistem administrator dapat dilihat pada tabel 4.1 sebagai berikut :

Tabel 4.1 Pengujian Login

\begin{tabular}{|c|l|l|l|}
\hline $\begin{array}{c}\text { Skenario } \\
\text { Pengujia } \\
\text { n }\end{array}$ & $\begin{array}{c}\text { Test } \\
\text { Case }\end{array}$ & $\begin{array}{c}\text { Hasil } \\
\text { Yang } \\
\text { Diharap } \\
\text { kan }\end{array}$ & Hasil Pengujian \\
\hline \multirow{2}{*}{ Login } & $\begin{array}{l}\text { Akses } \\
\text { link } \\
\text { admini } \\
\text { strator }\end{array}$ & $\begin{array}{c}\text { Menampi } \\
\text { lkan } \\
\text { tampilan } \\
\text { login }\end{array}$ & \multicolumn{2}{|c|}{ Admin Website } \\
\hline
\end{tabular}
password, jika terjadi username dan password salah maka akan muncul keterangan login gagal username dan password salah, jika benar akan diarahkan langsung ke menu dashboard.

b. Hasil PengujianData Produk

Adapun pengujian data produk pada sistem administrator dapat dilihat pada tabel 4.2 sebagai berikut : 


\section{RANCANG BANGUN PENGOLAHAN DATAPADA DESA BATU TERING SEBAGAI MEDIA PROMOSI DAN INFORMASI WISATA BERBASIS WEB}

Tabel 4.2 Pengujian Data Produk

\begin{tabular}{|c|c|c|c|}
\hline $\begin{array}{c}\text { Skenario } \\
\text { Pengujia } \\
\text { n }\end{array}$ & $\begin{array}{c}\text { Test } \\
\text { Case }\end{array}$ & $\begin{array}{c}\text { Hasil } \\
\text { Yang } \\
\text { Diharap } \\
\text { kan }\end{array}$ & Hasil Pengujian \\
\hline $\begin{array}{c}\text { Membuk } \\
\text { a master } \\
\text { data } \\
\text { produk }\end{array}$ & $\begin{array}{c}\text { Akses } \\
\text { link } \\
\text { admini } \\
\text { strator }\end{array}$ & $\begin{array}{c}\text { Menampi } \\
\text { lkan } \\
\text { tampilan } \\
\text { data } \\
\text { produk }\end{array}$ \\
\hline
\end{tabular}

Pada data produk terdapat tambah data, kemudian akan muncul di data produk yang sudah di input.

\subsubsection{Pengujian Sistem User}

Pengujian perangkat lunak pada sisten user terdiri dari menu Home, profil, produk desa, kependudukan, potensi dan kontak.

a. Hasil Pengujian Menu Home Pada Sistem User Adapun pengujian home pada sistem user dapat dilihat pada tabel 4.3 sebagai berikut :

Tabel 4.3 Pengujian Menu Home

\begin{tabular}{|c|c|c|c|}
\hline $\begin{array}{c}\text { Skenari } \\
\text { o } \\
\text { Penguji } \\
\text { an }\end{array}$ & $\begin{array}{l}\text { Test } \\
\text { Case }\end{array}$ & $\begin{array}{c}\text { Hasil Yang } \\
\text { Diharapka } \\
\text { n }\end{array}$ & Hasil Pengujian \\
\hline home & $\begin{array}{c}\text { Akses } \\
\text { link } \\
\text { user }\end{array}$ & $\begin{array}{c}\text { Menampilk } \\
\text { an tampilan } \\
\text { home pada } \\
\text { web }\end{array}$ & 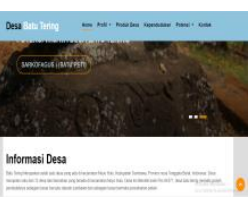 \\
\hline
\end{tabular}

Pada menu home terdapat sleader berupa foto,kode pos dan tampilan semua menu pada web.

b. hasil pengujian menu produk

Adapun pengujian menu Produk Desa tersebut dapat dilihatpada sistem user pada tabel 4.4 sebagai berikut :

Tabel 4.4 Pengujian Menu Produk Desa

\begin{tabular}{|c|c|c|c|}
\hline $\begin{array}{c}\text { Skenari } \\
\text { o } \\
\text { Penguji } \\
\text { an }\end{array}$ & $\begin{array}{c}\text { Test } \\
\text { Case }\end{array}$ & $\begin{array}{c}\text { Hasil Yang } \\
\text { Diharapka } \\
\text { n }\end{array}$ & Hasil Pengujian \\
\hline $\begin{array}{c}\text { Produk } \\
\text { desa }\end{array}$ & $\begin{array}{c}\text { Akses } \\
\text { link } \\
\text { user }\end{array}$ & $\begin{array}{c}\text { Menampilk } \\
\text { an tampilan } \\
\text { produk } \\
\text { desa pada } \\
\text { web }\end{array}$ & \\
\hline
\end{tabular}

\section{KESIMPULAN DAN SARAN}

5.1 Kesimpulan

Dari hasil analisis dan perancangan Pengolahan Data yang telah dilakukan sebelumnya, maka peneliti dapat mengambil kesimpulan bahwa Rancang Bangun Pengolahan Data pada Desa Batu Tering sebagai media promosi dan informasi wisata berbasis web telah selesai dibangun menggunakan bahasa pemrograman PHP dan database Website. Dengan Webiste ini pihak Desa dapat memberikan informasi untuk mempromosikan produk dan potensi berupa SDM,wisata,budaya sehingga masyarakat dapat dengan mudah mengakses informasi pada Desa Batu Tering. Selain itu terdapat pula layanan yang memudahkan mayrakat untuk memperoleh produk unggulan desa yang bisa di pesan langsung lewat web Desa,

\subsection{Saran}

Dari hasil pengolahan data pada Desa Batu Tering sebagai media promosi dan informasi wisata berbasis web, penulis memberikan saran untuk pengembangan berikutnya agar pada tahap kedepanyan dilakukan pengembangan web diantara lain meliputi :

a. Lebih mengkomplekskan pengolahan data agar dapat dengan langsung membayar lewat web.

b. Menambah beberapat fitur atau proses pada web agar lebih kompleks lagi.

\section{Daftar Pustaka}

Prof.Drs.Widjaja,HAW.2003.Pemerintahan Desa/Marga. PT.Raja Grafindo Persada.Jakarta.

Rangkuti, F. 2009. Strategi Promosi yang Kreatif dan Analisa KasusIntegrated Marketing Communicaion. Jakarta:Gramedia.

Yuhefizar.2008.10 Jam Menguasai Internet Teknologi dan Aplikasinya. Jakarta: PT.Elex media Komputindo.

Pressman, Roger S. 2015. Rekayasa Perangkat Lunak Pendekatan Praktisi Buku I. Yogyakarta: Andi

Arsyad. (2011). Perancangan Sistem informasi Parawisata Berbasis Web Di Dinas Kebudayaan Dan Pariwisata Kabupaten Muna. Jakarta Universitas Negeri Syarif Hidayatullah

Amelia (2015). Perancangan Media Promosi PT Petronika Sebagai Upaya Pembentukan Citra Perusahaan. Surabaya: Sekolah Tinggi Ilmu Komunikasi Surabaya. 